\title{
REFLECTIONS \\ From the pursuit of excellence to the quest for significance: Promotion of a Childsafe South Africa
}

\author{
A B (Sebastian) van As, Alastair J W Millar
}

Trauma represents a major burden of disease in South Africa. Children are disproportionately affected by trauma; rightly, childhood trauma can be referred to as 'the neglected childhood killer disease'. Unlike the field of infectious diseases, where vaccinations and prevention are the norm, paediatric trauma is usually ignored and prevention strategies are scarce. In this article, we review paediatric trauma and its effect on our society in light of the development of more effective child safety promotion strategies.

S Afr Med J 2012;102(6):427-428.
Injuries suffered by children have long been neglected and are largely ignored by health intervention initiatives such as the Millennium Development Goals. Numerous programmes related to child survival exist that target infectious diseases (such as HIV/AIDS and tuberculosis), malnutrition and gastroenteritis. However, child injuries continue to receive little attention. ${ }^{1}$

Against the backdrop of the call from the Commission for Africa in 2005 for a shift of emphasis from humanitarian relief to prevention, ${ }^{2}$ it is encouraging that provincial and national Ministers of Health (Ministers Botha and Motsoaledi, respectively) have begun to emphasise the importance of preventive healthcare.

\section{Trauma in South Africa}

According to the World Health Organization (WHO), trauma will be the biggest killer by 2020 as infectious and cardiovascular diseases decline. ${ }^{3}$ Approximately 5 million deaths, the equivalent of 50 Boeing jumbo jets crashing daily, occur globally each year as a result of injuries. ${ }^{3}$ In South Africa the most common causes of death are related to motor vehicle crashes, firearms and sharp and blunt assault. Unsurprisingly, South Africa has become a world leader in trauma care and extends training to a large number of under- and postgraduates from elsewhere in Africa and the world.

\section{Paediatric trauma care in Cape Town}

South Africa has a population of approximately 50 million, of whom 20 million are children aged $<18$ years. Trauma is the leading cause of childhood death in this age group. Annually, approximately 1 million children die worldwide from 3 big killers: motor vehicle accidents, drowning and burns. ${ }^{4}$ Low- and middleincome countries are particularly vulnerable. In South Africa it is estimated that at least 6500 children aged 1 - 14 years die each year as a result of unintentional injuries; this rate is 10 times higher than that in European countries. Our own research shows that a child

Professor Sebastian van As is Head of the Trauma Unit, Red Cross War Memorial Children's Hospital, School of Child and Adolescent Health, University of Cape Town. Professor Alastair Millar is the Charles Saint Professor of Paediatric Surgery, Red Cross War Memorial Children's Hospital, School of Child and Adolescent Health, University of Cape Town. growing up in Cape Town is 25 times more likely of being admitted to hospital with an injury than a child growing up in Birmingham, UK (Childsafe South Africa - unpublished research data).

It has been well established that injured children treated in dedicated paediatric trauma centres have better outcomes than those treated in 'adult' trauma centres; ${ }^{5}$ therefore, the development of paediatric trauma care is an area where paediatric surgeons have pursued excellence and taken leadership. In 1984 the first paediatric trauma unit was established at Red Cross War Memorial Children's Hospital under the auspices of the Department of Surgery. The unit consisted of 10 beds, its own resuscitation room, radiology suite and operating theatres for children aged $<13$ years. Initially under the leadership of a general surgeon, staffing soon included 2 orthopaedic surgeons, with close liaison with all the surgical specialties and a paediatrician to assist with child abuse cases. Thirty years after its inception, the trauma unit treats approximately 10000 children annually, of whom an average of 2800 are seriously injured and require admission. ${ }^{6}$ Approximately 1200 operations are performed annually, of which orthopaedic procedures are the most frequent.

With the support of the Red Cross War Memorial Children's Hospital Trust and its donors, a state-of-the-art trauma unit was opened in 2004. It is currently the only paediatric trauma unit with a total body scanner (Statscan - low-dose radiation digitalised total body scanner) capable of taking a complete radiographic image of a child's body in $<13$ seconds without the need to move the patient from the resuscitation trolley. This is useful in children presenting with multiple injuries, and has been a major advance in emergency trauma care for our children.?

\section{Child safety promotion}

The Child Accident Prevention Foundation of Southern Africa (CAPFSA), one of the first such agencies in the world, was established at Red Cross War Memorial Children's Hospital by Professor Sid Cywes, who presciently saw the need for a prevention strategy and improvement in trauma care. ${ }^{8}$ The organisation has been warmly supported by the Department of Health in the Western Cape since its inception.

Renamed to Childsafe South Africa in 2008, the agency's vision is to create a safer world for children. Activities focus on research, education, environmental change and recommendations for legislation ${ }^{9}$ aimed at increasing awareness of the trauma epidemic and strategies to prevent injuries.

Initiated in 1991, the Childsafe South Africa electronic injury database on incident and clinical details has demonstrated that the most common modes of violence against children are blunt assaults, followed by sexual assault, sharp assault and bite wounds. The most frequent causes of mortality are motor vehicle accidents (mostly 
pedestrian), burns and drowning. This is the largest (single-centre) childhood injury database in the world with over 160000 entries, each with approximately 50 variables.

Furthermore, Childsafe South Africa focuses on education and awareness with an annual national child accident prevention month, providing child safety courses to the community. The agency also publishes a quarterly Childsafe Newsletter, runs extensive media campaigns (with an annual media coverage excessing R20 million) and maintains a popular website offering information on childsafe practices (http://www.childsafe.org.za).

Support for the new child-friendly Firearms Act was one of the most prominent activities of Childsafe South Africa. As a result of the act, the number of gunshot injuries to children treated in our hospital has been reduced by $70 \%$; mortality from gunshot injuries has declined by roughly $50 \%$ since 2000 .

The ongoing requirement for promotion of child safety, education and law enforcement is illustrated in Childsafe South Africa's publication in the $S A M J,{ }^{10}$ which exposes the vast public ignorance of the consequences of the lack of seatbelt restraint in a motor vehicle crash. Of child car passengers requiring treatment at the trauma unit of Red Cross War Memorial Children's Hospital, 87\% were unrestrained. A survey of children travelling to the hospital by car showed that $89 \%$ were unrestrained.

Childsafe South Africa was instrumental in the development of the World Report on Child Injury Prevention ${ }^{3}$ and was a major contributor to the findings of the report published by the WHO in December 2008, advocating the co-ordination of activities of relevant sectors (such as non-governmental organisations, academic institutions and the private sector) and the establishment of a global agenda for the prevention of childhood injuries.

\section{Conclusion}

There is growing evidence of the extent to which child injury is a major public health problem and of the specific risk factors for such injury. Often such risk factors can be easily addressed; simple improvements to playgrounds may enhance safety while obvious social adjustments may provide parents with more parenting/childcare time. ${ }^{1}$

Child injury is less commonly the result of intentional abuse and maltreatment than of unawareness of how vulnerable the child is to injury and appreciation of the need for appropriate interventions. While a range of potential interventions have been shown to be effective and cost-efficient, more research into the mechanisms of childhood injury and the circumstances in which they occur is warranted. In 2012 paediatric healthcare providers are at the forefront of promoting a shift from curative to preventive care.

1. Van As AB, Stein DJ. Child safety: a neglected priority. World J Pediatr 2010;6(4):293-295.

2. Commission for Africa. Our Common Interest; Report of the Commission for Africa 2005. http:// webarchive.nationalarchives.gov.uk/20050606200944/http://www.commissionforafrica.org/english/ report/thereport/english/11-03-05_cr_report.pdf (accessed 9 January 2012).

3. Peden M, Oyegbite K, Ozann-Smith J. World Report on Child Injury Prevention. Geneva: WHO and UNICEF, 2008. http://www.who.int/violence_injury_prevention/child/en/(accessed 9 January 2012). 4. Van As AB. Paediatric trauma care. Afr J Paediatr Surg 2010;7(3):131-135.

5. Oyetunji TA, Haider AH, Downing SR, et al. Treatment outcomes of injured children at adult level 1 trauma centers: are there benefits from added specialized care? Am J Surg 2011;201(4):445-449.

6. Van As S. The health of our children should be the measure of our progress. South African Journal of Child Health 2010;4(1):5-6.

Pitcher RD, Wilde JCH, Douglas TS, van As AB. The use of the Statscan digital X-ray unit in paediatric polytrauma. Pediatr Radiol 2009;39(5):433-437.

8. Van As S. Global factors affecting child trauma and the need for ongoing child advocacy. Vulnerable Children and Youth Study 2011;6(4):277-283.

9. Childsafe South Africa. http://www.childsafe.org.za (accessed 9 January 2012).

10. Kling J, Nicholls T, Ntambeka P, van As AB. Restraint use for child passengers in South Africa. S Afr Med J 2011:101(3):146.

Accepted 23 January 2012. 